\title{
ANDRÉS SÁNCHEZ ROBAYNA Y LA LUZ INSULAR
}

\author{
Claude LE BIGOT \\ Université de Rennes 2 - Haute Bretagne \\ No es suficiente lo visible. \\ ASR
}

$\mathrm{H}$

ace tiempo, ya con motivo de una reflexión sobre la insularidad en la poesía canaria, apoyé mi interpretación en la doble referencialidad de lo insular, que remite por un lado a lugares concretos del paisaje canario y que por otro lado encuentra en la poesía de Sánchez Robayna un esbozo personal de cariz ontológico (Le Bigot, 2000: 133-142). Hoy quisiéramos profundizar una reflexión limitada al ámbito de la poesía robayniana partiendo de las mismas bases, pero mirando hacia una poética de la percepción, la cual tiende a comunicar al lector una experiencia de la creación, muy afín a los planteamientos fenomenológicos que han de permitir aunar tres realidades nucleares en cualquier experiencia poética: sensación, imagen, remembranzas. Ahora bien, la obra poética de Andrés Sánchez Robayna desde sus inicios otorga a la imaginería insular un sitio importante con visos transcendentes, que al filo de los poemarios acabarán por configurar una visión personalísima y coherente del mundo basado en una portentosa intuición de los intercambios intercambio de papeles entre el cuerpo y el espíritu, entre lo imaginario y lo real-, que había de alcanzar su culminación en la sección «Sobre une confidencia del mar griego» de la última entrega del poeta canario incluida en La sombra y la apariencia (2010). Esa reversibilidad de las sensaciones viene condensada en cierta antropomorfización del mar cuya percepción constituye de por sí un interrogante sobre el origen de lo que aflora a la conciencia:

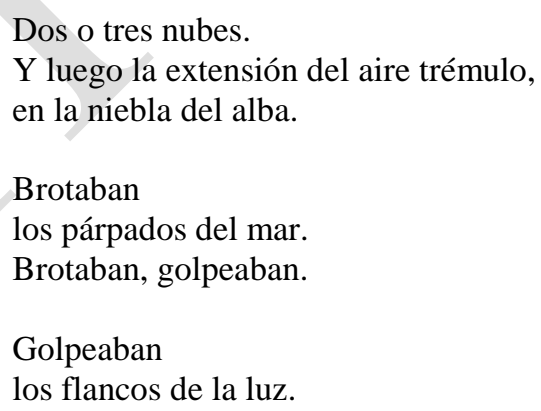


Lo que merece nuestra atención es el examen de los vínculos que Sánchez Robayna establece entre el ser, las cosas del mundo, la relación con nuestro semejante, que son operaciones del pensamiento que tan sólo cobran realidad mediante la palabra desde un lenguaje en permanente fluencia. Todo este enlace de realidades insulares -y nos consta que lo insular funciona como microcosmo del universo- apuntaladas por las figuras del discurso, vertebran lo que el propio poeta llama «la pulsión de espacio» (Sánchez Robayna, 2004: 433). Tales contemplaciones ensanchan la visión, y como cualquier visión al ser cierre y apertura, ésta empuja al sujeto contemplador a modificar su manera de mirar al mundo:

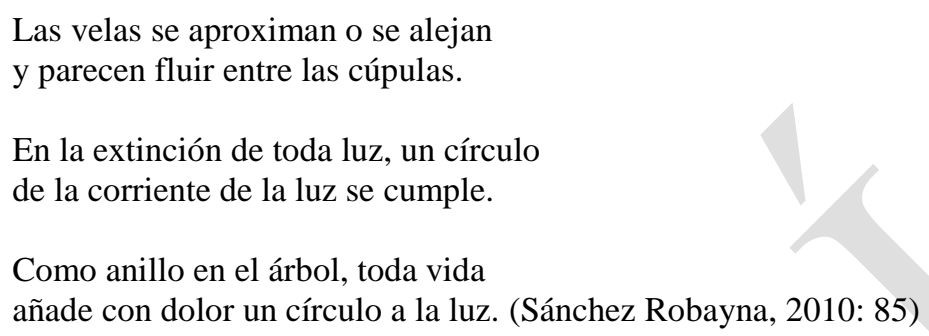

Cabe preguntarse si el horizonte de significado abierto por la palabra va más allá de lo que permitía la retórica antigua, acudiendo a personificaciones, analogías o comparaciones. Para contestar la pregunta, o por lo menos aclarar lo que simboliza la luz insular robayniana, proponemos indagar los dos puntos siguientes como etapas de una experiencia de la creación: la configuración de lo visible, o nacimiento de la forma, y como etapa final, el paso de lo sensible a lo metafísico.

\section{La configuración de lo visible o nacimiento de la forma}

Todo lo que se puede decir de la visión del paisaje en la obra de Sánchez Robayna abarca un entretejido de sensaciones al que acude el poeta en sus primeros versos, especialmente en el poema inaugural de su poesía reunida, En el cuerpo del mundo. Abre la recopilación un poema titulado «Día de aire» en el que se inicia lo que el filósofo francés Merleau-Ponty llamó «la venida a sí de lo visible» y que ofrece al lector un «condensado del universo» (Merleau-Ponty, 2010: 28). Bajo una formulación un tanto complicada, el filósofo francés desarrolla un planteamiento perfectamente coherente, desde el cual la fantasía del artista (pintor o poeta) unifica fuera de cualquier convención, dejándose llevar por la «localidad global» (Merleau-Ponty, 2010: 65) que autoconforma la mirada del poeta. La primera estrofa del poema arriba mencionado es explícita bajo una formulación extraña, que va en contra de la experiencia común:

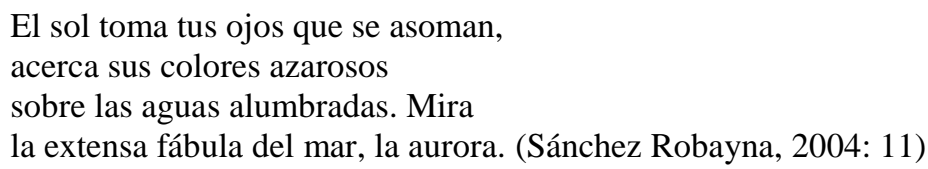

Pasando del concepto de «localidad global» a consideraciones más próximas a la experiencia común, un comentarista de Sánchez Robayna veía en la «insularidad» de la lengua, la metáfora capaz 
de plasmar el principio que unifica la expresividad infinita de la materia. Así surge, según José Francisco Ruiz Casanova, un discurso incoativo o genésico que aúna «rocas, luz, médanos y la orilla del mar», trayendo a colación una cita del mismo poema :

Excavas en la orilla la palabra

que dice el mar soplado. La palabra

que late desde el fondo de la roca. (Sánchez Robayna, 2004: 12)

Hay que reconocerle al crítico el haber intuido con acierto no una mera poética, sino la extrema relevancia de la fusión entre poesía y paisaje: «Se anuncia, pues, el comienzo de la quête; el poema preámbulo no es, en esta ocasión, el pórtico de una poética preformulada, sino, más bien la antesala de un viaje sin más ruta que la brújula que señala que la palabra debe alzarse como el paisaje de su poesía» (Ruiz Casanova, 2012: 36). Esta última cita pone de relieve el papel que ha de desempeñar la palabra como mediación en la constitución del paisaje. Un cotejo entre la técnica del pintor de hoy y el poeta se impone para ver una similitud experiencial compartida: el hecho de que ambos se dejan fecundar por un telón de fondo, múltiple, disperso y abigarrado. Lo que les afecta es el experimentar el tremor de las cosas incipientes. De pronto sale a la luz la posibilidad de captar las cosas del mundo y darlas a conocer según una perspectiva infinitamente abierta, como en un perpetuo amanecer. De ahí, como consolidación de una visión personalísima, pero universalizable como experiencia, la escena de una geología escondida sugerida por el poema inaugural de Tinta (1981), «Unidad»:

\footnotetext{
Desde la ventana, todo respira y se responde: el vuelo circular de una golondrina, la tunera reseca, el cardón erecto, la sombra fugitiva de la golondrina, el arco de la pata del gato en la roca soleada -el salto sigiloso, misterioso-, las ramas secas, el murmullo cada vez más denso, las palabras que acalla el soplo ardiente, el golpear del viento de las seis de la tarde al fondo del barranco» (Sánchez Robayna, 2004: 97).
}

Se habrá observado la adjetivación plástica, el cromatismo transicional, el dinamismo sensorial, convocados con una voluntad si no simbólica, por lo menos expresiva, que apunta una idea paradójica -constante en la obra de Andrés Sánchez Robayna- : pese a la «unidad» proclamada desde el título, el mundo ya no puede ser la totalidad aritmética de los objetos.

Quisiera insistir en un aspecto tal vez infravalorado por los comentaristas y estudiosos de la obra robayniana: la ambivalencia de la percepción del paisaje en el momento de su representación. Lo más a menudo los críticos optaron -impulsados por la evidente ligazón entre paisaje y escritura, que establece el propio poeta- por una lectura metaliteraria de los poemas de Robayna. No es que sea un error, pero hay que detenerse más en el principio que vertebra el paisaje poético, recordando que un paisaje literario no existe fuera de la «alianza necesaria entre lo interior y lo exterior, ya que se define por el punto de vista de un sujeto sobre el mundo» (Collot, 2005: 69). La llamada «estructura de horizonte» teorizada por Michel Collot, nos enseña que más que una fidelidad al modelo, lo que se impone es la calidad de la mirada individual que acaba por «pautizar» lo observado, más o menos fantaseado por el artista, el cual no deja de proyectar en el paisaje lo que su sensibilidad e intelecto le dictan. ¿Cómo se ha de interpretar el final del poema «Tinta», con el que Robayna delinea perfectamente las etapas que van de la percepción de un paisaje a lo que el poema transcribe 
comunicando al texto este roce misterioso que procura «el tejido de la ventisca hendedura invisible» (Sánchez Robayna, 2004: 112)? Por más que se captan realidades tangibles (paseo de palmeras, arboleda, cielo negro, claxons lejanos, rumor de los tilos, etc.), la mirada sólo alcanza un trasfondo u horizonte; y el horizonte es a un tiempo lo que limita la mirada y le abre el infinito, el vacío, el enigma. Apuntar este hueco («la hendedura invisible») es una manera de circunscribir la aporía del poema: ¿cómo aunar, tejer lo tangible (la huella que el escritor deja en la página y la experiencia de quien se queda absorto en la contemplación del paisaje) con una realidad huidiza, que siempre escapa de cualquier posibilidad de cierre? La última parte del poema epónimo «Tinta» mimetiza por su fluidez sintáctica y fraseo de constelación múltiple la distancia insalvable entre referente y signo distancia subrayada aún por el sangrado entre los dos bloques de oraciones:

el cielo negro y su escritura blanca cerrados sobre el paseo de palmeras se vierten se tienden se escriben la arboleda tamiza el ruido de los claxons lejanos apagado sonido respuesta escrita en el tejido de la ventisca hendedura invisible

otro el texto que desconstruye y se agita y se enarca-

cerca del rumor de los tilos

la noche-

la tinta- (Sánchez Robayna, 2004: 112).

Robayna da a entender que lo que dice el poema en el momento de la representación no puede mantenerse en lo abstracto, lo inmaterial, sino que ha de volver al lugar del enraizamiento preciso desde el cual el paisaje está captado («cerca del rumor de los tilos»).

Existe, pues, un reto ideológico en la representación del espacio insular, que Robayna no quiere acotar en los límites de un marco de cuño realista; opta más bien por la representación más abierta, -que el archipiélago metaforiza- y que por definición abarca el horizonte más amplio, el lugar mismo de lo imaginario.

Si se ha establecido tan frecuentemente a propósito de la poesía de Robayna, a partir del tríptico Clima, Tinta, La roca, una equivalencia entre la luz y el signo, acaso sea necesario explicar cómo pasamos de la percepción a la visión. En esto, nos consta que Sánchez Robayna tiene asimilados plenamente los planteamientos de Merleau-Ponty, especialmente las enseñanzas que el filósofo francés saca de su reflexión sobre la pintura de Klee y Cézanne para comprender cómo se construye el espacio, cuando se renuncia a la perspectiva que el Renacimiento impuso como técnica. Un poema de Tinta expone este paso de la perspectiva a la profundidad, o sea cómo la luz crea un espacio que contiene y envuelve al individuo, foco de la visión:

Fluye, fluye sin fin, oh tejido invasor, oh red que ciernes. Fluye secamente de toda ausencia oscura. Fluid, rayos extensos, sobre los arenales. Salid densamente de la ausencia, sed, ahí, llamas en el trono del ojo. [...] Que venga tu rumor de fibras y de lacas en la hora altiva sobre los médanos. Ahí están los maderos, los corchos y las planchas de cobre bajo el cielo segmentado y rodante, y las olas, y el polvo; también ellos te aguardan. Da, luz, tu paso entero. Llégate hasta la lengua que jadea. Sé el agua de esta nada. (Sánchez Robayna, 2004: 102).

La luz da forma a los objetos; pero lo que sucede en el poema arriba citado, tiene otra dinámica: el discurso del poeta no habla del espacio y la luz, sino que deja el espacio y la luz cobrar 
consistencia, espesura, presencia: «Salid densamente de la ausencia, sed, ahí, llamas en el trono del ojo.» (Sánchez Robayna, 2004: 102). Insistir en el surgimiento de la visión, como lo hace Andrés Sánchez Robayna, es como poner en el centro de su reflexión un enseñoreamiento de lo sensible como fundamentos de nuestra relación con el mundo. No sería exagerado decir que la filosofía implícita a la que suscribe Robayna, esboza una dialéctica entre lo tangible y lo visible, reparándose en la posibilidad que ofrece la poesía de abrir el ser a la pluralidad simultánea de la presencia del mundo.

Todo lo dicho hasta aquí sobre la mirada y su apertura perceptiva a lo fenomenológico nos lleva a pensar que el referente insular, tan frecuente a través de un léxico consabido, no sólo es lo más importante de la significación sino que va cobrando una dimensión más profunda, de cariz metafísico. Este giro que los estudiosos señalaron a partir de Palmas en la losa fría (1989) zanja definitivamente cualquier relación con un exotismo de poca monta, que en realidad nunca se dio en la obra de Robayna, y que llevaba en ciernes desde sus comienzos una «teleología de la insularidad», para decirlo con las palabras de Lezama Lima, o sea algo más que cierto simbolismo, un anhelo de indagación que tiende a alumbrar el misterio de los orígenes. Pero no lo hace Sánchez Robayna en términos religiosos, habitados por un catolicismo apostólico y universal, sino absorto en el conocimiento de lo interior humano. Este interior humano no tiene relación homológica con el paisaje, tipo «paisaje/estado de ánimo» tal como lo había impuesto el Romanticismo. Lo que Robayna intenta asentar con mayor precisión en Palmas sobre la losa fría, es su experiencia de lo sensible como desvelamiento de un sentido. Entre la luz estelar y la luz meridiana, el poeta crea una trayectoria tensional de designación de los objetos de nuestro entorno: entre lo naciente, lo apenas perceptible y la presencia tangible, existencial, que sólo la palabra logra formalizar:

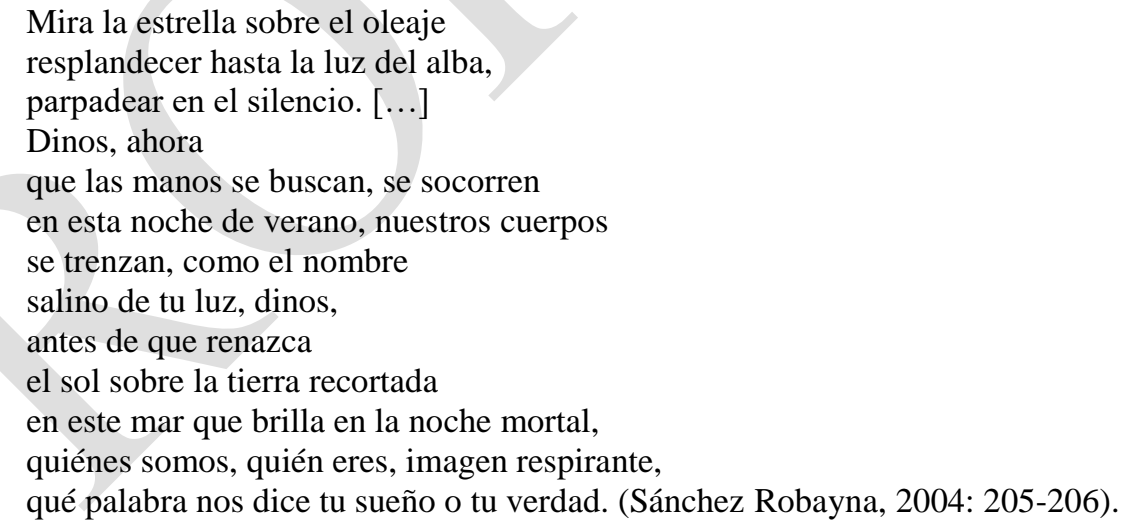

El Ser de que nos habla Robayna se define tan sólo a partir del contacto con los objetos. El contacto supone la distancia y el vacío. En Totalité et infini, el filósofo Emmanuel Levinas se pregunta si

[...] ce vide spatial n'est pas un 'quelque chose', la force de toute expérience [...] L'espace éclairé n'est pas l'intervalle absolu. Le lien entre vision et toucher, entre représentation et travail demeure essentiel. La vision se mue en prise. La vision s'ouvre sur une perspective, sur un horizon et décrit une distance franchissable, invite la main au mouvement et au contact et les assure. (Levinas, 1990: 205-206) 
La importancia que Robayna concede a lo sensible, aglutinado en torno a una serie de realidades elementales (sol, roca, mar, agua cielo VS mano, voz, hombre, rostro, ojos, cuerpo) fundamenta una conciencia perceptiva que sólo se conforma al vivir en el mundo, tejiendo en él los lazos que la constituyen.

\section{El paso de lo sensible a lo metafísico, o hacia una «teología de la luz»1}

El utillaje fenomenológico convocado hasta ahora para ver cómo se organiza el paisaje no puede prescindir del trasfondo metafísico que lo fundamenta. Un acercamiento algo precipitado al tema de lo visible VS lo invisible podría llevarnos a pensar que estamos ante un nuevo avatar de la búsqueda de las esencias. Al centrar lo sensible en lo que la luz deja vislumbrar, Sánchez Robayna hace de ella el origen de cuanto captamos en nuestro entorno. Así el origen se confunde con lo oscuro, lo ilimitado, lo Otro, Dios o el alma, apostando que la poesía será una «vía de salvación» para mantener a flote la tenue esperanza de que el canto (sea himno esperanzado y confiado, sea lírico, dicho de otro modo condenado al lamento de la pérdida) siga haciendo el mundo habitable o respirable. Cotejando las ideas de Gottfried Benn con su propia poesía, Andrés Sánchez Robayna escribe:

Dije en un poema: la medida es oscuridad. La oscuridad o la luz o tal vez la oscura luminosidad, en fin. Pues no se trata ahora de ello, sino de la medida: qué límites descubre la lengua del poema respecto de lo real. O quizá: cómo la lengua viene a significar la ruptura de toda medida y proponerse como la desmedida misma. (Sánchez Robayna, 1996: 210-211).

Tales palabras apuntan el oblicuo proceder del lenguaje poético que sólo de forma asintótica designa el fondo de lo invisible o de lo indecible. Acaso lo dicho en este diario se encuentre condensado bajo la forma de una poética en un texto de La sombra y la apariencia:

Caminarás, el sol

del final del verano

sobre la tierra casi sin sombra alguna,

por las piedras hirvientes

que recogen

la luz, inmensurable,

y la destruyen.

Habrá pasado el tiempo.

Allí, junto al olivo,

alguna cosa ,

tal vez una esperanza,

\footnotetext{
${ }^{1}$ Reconocemos nuestra deuda a Serge Champeau por el marco conceptual epistemológico que nos ofrece en su análisis de la percepción y conformación del paisaje, apuntalado en el estudio de la obra del poeta francés Philippe Jaccottet. Le debemos la idea de «teología de la luz» como trasfondo metafísico de que bajo lo sensible se oye la voz de lo indecible. Nos consta que esta idea bien puede aplicarse a la poesía de Andrés Sánchez Robayna. (S. Champeau, Ontologie et poésie. Trois études sur les limites du langage. Véase en particular «Paysage, âme, poème», pp. 169-195.)
} 
te será dada. (Sánchez Robayna, 2010: 125).

Permanentemente, Andrés Sánchez Robayna evoca este lugar tensional que caracteriza lo insular, abierto y cerrado a un tiempo, convocando junto a esta polaridad otras como tierra y cielo, claridad y oscuridad. La cita pone de realce la ósmosis entre el mineral y la luz en los momentos transicionales (amanecer, cenit, atardecer) «por las piedras hirvientes / que recogen / la luz, inmensurable, / y la destruyen.» (Sánchez Robayna, 2010: 126). Va a oponer el poeta en la parte siguiente del díptico la idea cíclica de que el tiempo que nos escapa, se salva cuando se lo puede transformar en lugar, como si la fijación de un lugar por la palabra le diera un asentamiento estable y duradero: «algo que no está allí / y está, como los muertos / y el sol, / en lo perpetuo» (Sánchez Robayna, 2010: 126). El paisaje insular va cobrando una función metafísica o teológica. En su ensayo Ontologie et poésie, S. Champeau echó las bases de una teoría del paisaje que encaja perfectamente con la «teoría de las islas» con la que Robayna vertebra su obra poética. El ensayista francés define dos tipos de tratamiento de la luz, o descenso hacia la tierra, o elevación hacia el cielo:

Le paysage -tel lieu, à tel instant- se donne comme une tension et une communication entre deux pôles, ciel et terre, clarté et obscurité. Cette communication prend deux formes essentielles. Elle est d'une part illumination, ou descente de la lumière vers la matière. Cela tantôt sous la forme d'une incarnation dans une matière préexistante, tantôt sous celle d'une émanation de la matière à partir de la lumière. Elle est d'autre part élévation : de la terre vers le ciel, de l'obscur vers la clarté. Tantôt comme une spiritualisation de la terre aspirant à la lumière, tantôt comme un épanouissement, une genèse de la lumière à partir de la terre. (Champeau, 1995: 172-173)

Semejante esquema bipolar también puede aplicarse al tratamiento de la luz en el poeta canario. El lector observará sin dificultad este doble movimiento: por una parte, la luz es iluminación de la materia, alumbramiento, en el doble sentido que tiene la palabra española de «disipar la oscuridad» y de «dar a luz». Por ejemplo, se detiene Andrés Sánchez Robayna en las horas matutinas en que la luz diseña los contornos del mundo circundante:

Por sobre toda redención, el sol

bebe en los cuencos pardos de la ansiedad de la tierra (Sánchez Robayna, 2004: 276)

Este mismo sol naciente permite el surgimiento de lo múltiple, que es la manera más común que corresponde a nuestra experiencia sensorial ${ }^{2}$. También, el poeta sabe captar todo el valor plástico que los pintores aprovechan para darles vida a sus lienzos, una luz que desde arriba hacia abajo manifiesta su presencia al diluirse en los objetos del mundo:

en la luz ciega de los bordes

lábil la luz la sombra fija

así su cuerpo escrito huye

tallada así la luz se abisma (Sánchez Robayna, 2004: 133).

\footnotetext{
${ }^{2}$ Posicionamiento aún más explícito en el poema «El despertar» de Fuego blanco: «Como la roca matinal en átomos / de albor, de luz despedazada, / bebe, cuerpo, el rocío de los mundos, / la luz parada sobre el mar». (Sánchez Robayna, 2004: 276)
} 
Por otra parte, la luz está evocada a través de su momento ascensional, como una elevación hacia el cielo, y la imaginería a la que acude Sánchez Robayna puede abarcar la floración, los estallidos, el vuelo de las aves y otras tantas cosas ligeras que invaden el espacio. Nos comunica el poeta esta experiencia y al mismo tiempo el significado que le asigna:

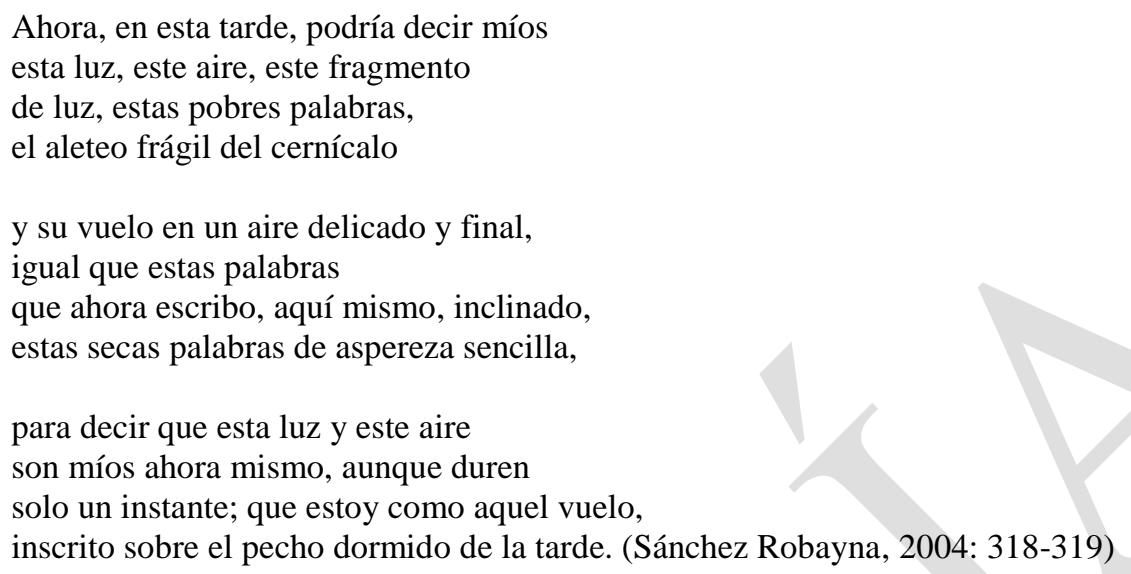

Acaso un poema que explicite con mayor nitidez la cosmología esbozada por Sánchez Robayna en Palmas sobre la losa fría sea el poema «El hombre hasta la claridad». Ahí dice el poeta:

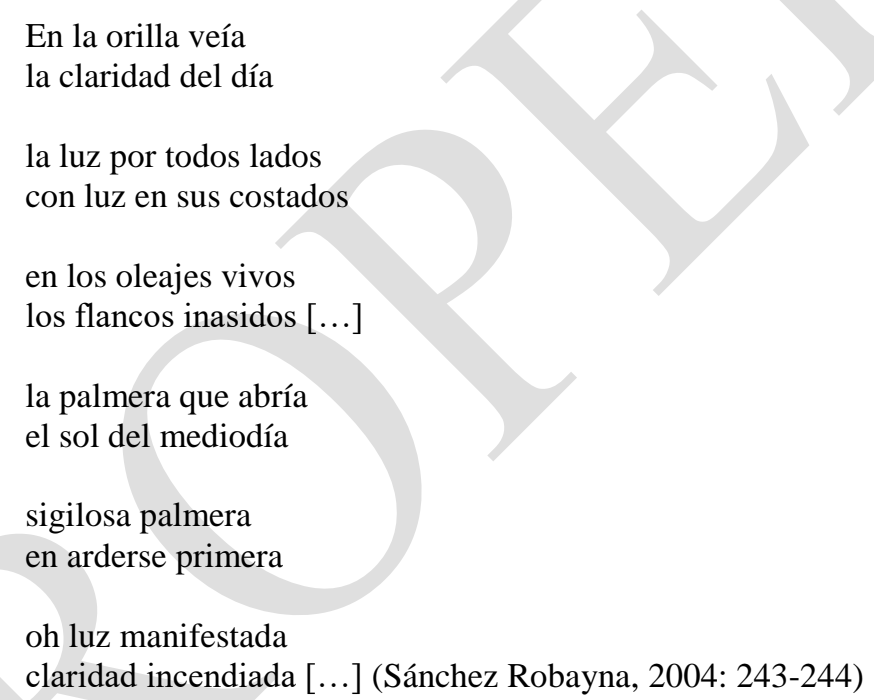

Tal profusión de luz que se extiende por el universo, sigue siendo un misterio al que se asoma el poeta. Por eso habla de la «arcana luz» y reforzando el misterio de su origen, el poeta designa la culminación del día como el punto que lo destruye todo como «el incendio», momento de vuelco que es un volver a los orígenes. De ahí tal vez ese «fuego blanco» que se hunde para renacer de sus cenizas tal como el Fénix: «pude ver la luz abrevar en lo oscuro [...]» (Sánchez Robayna, 2004: 290). ¿Qué significa esta inversión total que inicia, eso sí, un ciclo? ${ }^{3}$ La evocación de la luz llevada a su culminación es una vuelta al origen, a lo ilimitado («los bordes inasidos»), identificado

\footnotetext{
${ }^{3}$ Ciclo sugerido por la reiteración de los mismos versos al comienzo y al final del poema: «En la orilla veía / la claridad del día».
} 
explícitamente con la luz y el espíritu, o mejor dicho una materia espiritualizada que se manifiesta al poeta como «signo» y le recuerda que su ser tan sólo se conforma a partir de lo que se oculta bajo lo sensible. De ahí esta fusión que opera el poeta entre la luz y la materia, como zócalo constitutivo de la insaciable sed de superar el misterio: «Brotaban / los párpados del mar. / Brotaban, golpeaban. // Golpeaban / los flancos de la luz. // Esos signos herían.» (Sánchez Robayna, 2010: 73). Aún más, si estos signos aparentemente indescifrables persisten como manifestación de lo verdadero, lo auténtico, lo inmediato, el poeta ya no persigue una metafísica propiamente dicha, sino que asienta su reflexión en una fenomenalización del Ser, la cual intenta circunscribir a través de las formas del arte y del lenguaje. Y más lejos se interroga el poeta sobre la posibilidad de reducir el misterio que ha separado el lenguaje y la naturaleza, quitándose tal vez para siempre el acceso a una significación de lo sensible:

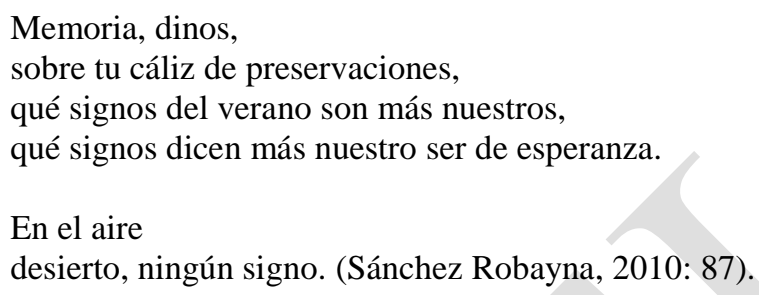

Barajaremos una hipótesis: bajo las apariencias metafísicas (que encontrarían su origen en una esencia del paisaje), las cavilaciones que cruzan la obra poética de Andrés Sánchez Robayna, y que tienen como núcleo aglutinante el centro de lo sensible, tienen algo que ver en realidad con una fenomenología muy coherente. El paisaje, captado de buenas a primeras a partir de su dimensión espacial (roca, médanos, palmeras, cielo, etc.) remite siempre al tiempo, y más allá del tiempo mesurable, a la conciencia de sí mismo. Esta conciencia viva y pujante acaba por confundirse con el tiempo inmemorial de la piedra. El poema «Sobre un trono de piedra» bien podría aparecer como la encarnación de la voluntad humana de situarse ante el infinito sin perderse en la añoranza de una totalidad inabarcable. Ahí plantea el poeta la pregunta sobre el «ser de esperanza» que es proyectarse en una exterioridad «qui permet de comprendre le sens du fini, sans que sa limitation, au sein de l'infini, exige une incompréhensible déchéance de l'infini» (Levinas, 1990: 325). Esta visión del ser humano mantiene a distancia una interpretación puramente teológica de la aventura humana:

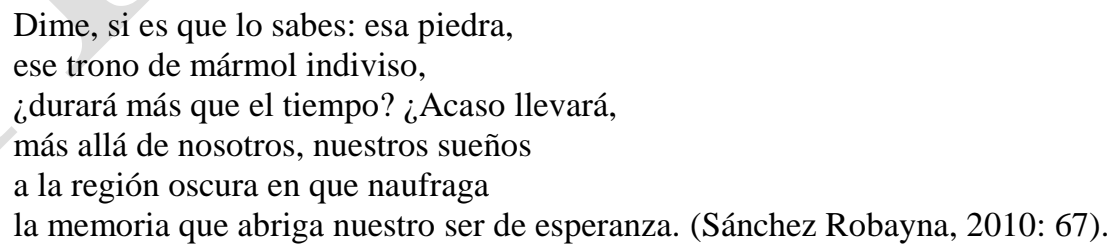

El ser es emanación de «nuestros sueños» (nuestros anhelos) y se construye en la punta de un deseo de infinito, que tan sólo se cumple en lo discontinuo y lo repetible: 
del origen y el fin, a la materia inmortal y materna. $\mathrm{Y}$ aunque sólo quedara de nosotros esa piedra, esa piedra dirá toda nuestra memoria (Sánchez Robayna, 2010: 68).

Los aspectos del paisaje en la poesía de Sánchez Robayna se temporalizan de manera paralela al espacio, muchas veces, de manera tensional. La roca, la materia son asimiladas a un pasado inmemorial, una marcha en la noche o hacia la muerte; o a la inversa, el árbol, el ave, la luz reflejan un lugar ameno o el surgimiento de un momento de sosiego. De modo que el centro de lo sensible no se deja localizar en un punto fijo, sino que se desplaza para ajustarse a las condiciones de posibilidad de los fenómenos sensibles, tanto existenciales (belleza, amor, goce) como imaginarios (los sueños del poeta acerca del centro de lo sensible):

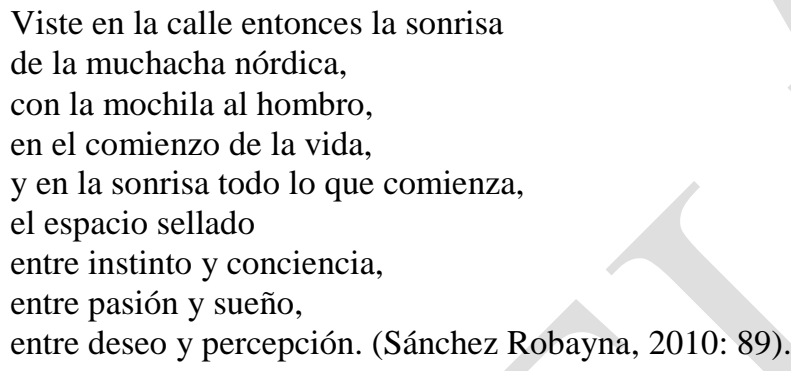

Tal vez sería imprudente identificar el centro de lo sensible con la consecución de la plenitud, un estado de bienestar insuperable. Hemos visto que la luz del mediodía es una luz hiriente, que tiende a borrar las formas; entonces el punto de equilibrio es un punto transicional que aúna espacio y tiempo en el mundo de tejas abajo y se plasma en la contemplación de los objetos más humildes de nuestro entorno. Tales objetos, contemplados, al calor de la luz, se «semiotizan» para manifestar la estructura de lo sensible. Serge Champeau concede a la palabra poética este poder heurístico: «L'insaisissable est l'accord qui relie les pôles spatiaux ou temporels, et par là fait apparaître le sensible dans sa structure» (S. Champeau, 1995: 188). Esta posibilidad de reunir los contrarios sería la enseñanza que aporta el libro Sobre una confidencia del mar griego ${ }^{4}$; ahí el poeta equipara lo vivido durante un viaje por el Mar Egeo con la insularidad canaria que configura su visión del mundo:

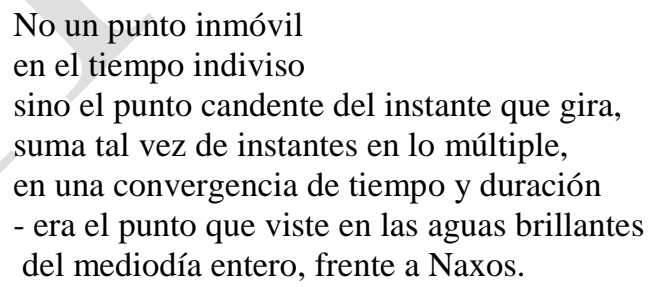

\footnotetext{
${ }^{4}$ Publicado primero como libro ilustrado con dibujos de Antoni Tàpies en 2005 (Madrid, Huerga y Fierro), ha sido integrado en La sombra y la apariencia, de la que forma la tercera sección.
} 
Las aguas te decían otra vez

su palabra ignorada. (Sánchez Robayna, 2010: 93).

¿Dónde situar este centro, que parece escaparle al poeta, y que sin embargo coincide con un momento sino de plenitud, por lo menos de satisfacción ${ }^{5}$, que ya vimos anteriormente, del cual el poeta da a entender que es un punto de convergencia entre el goce de vivir y la sensación del vacío, la tenue esperanza de un equilibrio de las tensiones, que corresponde al «espacio sellado / entre instinto y conciencia, / entre pasión y sueño, /entre deseo y percepción». Tal punto imposible de definir en su naturaleza, se deja acotar no obstante bajo la especie de un objeto concreto, que el poeta asocia con el acercamiento a la belleza, cifrada en una «casa de la luz», real o imaginada:

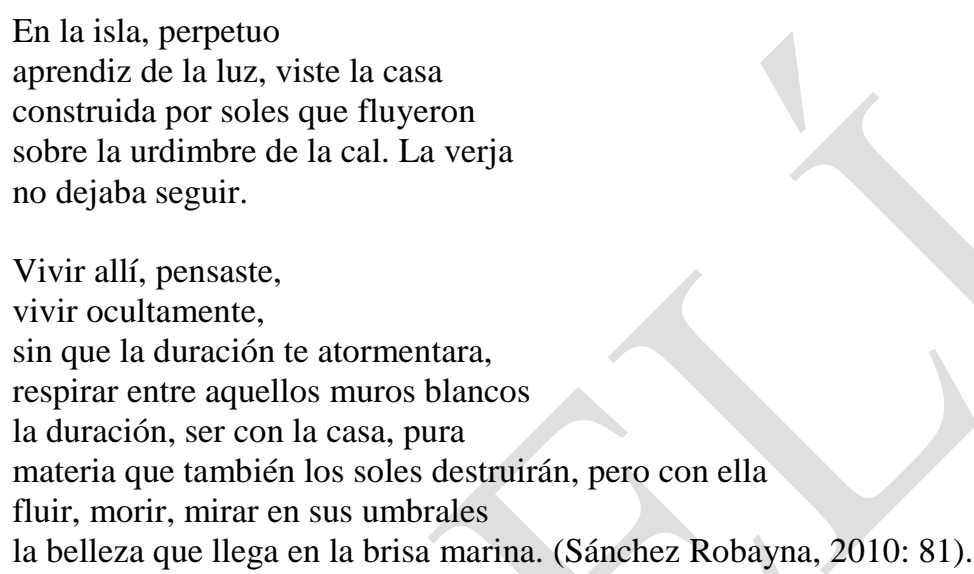

Es posible que no vaya más lejos la teología de la luz que Robayna viene desarrollando. La luz, origen de lo sensible, nos remite a nuestra propia identidad, al ser en el tiempo, en una trayectoria forzosamente limitada. Entonces, ¿qué pueden saber el arte o la poesía? Nada más que un momento fugitivo, un instante, y ese valor huidizo al que se asoma el arte, no puede fijarlo más que en la duración de un momento, condenado a repetirse en la obra por venir. De ahí tal vez, la sensación cíclica que evoca Sánchez Robayna en el poema citado arriba.

\section{Epílogo}

Reiteradas veces en su poesía, Andrés Sánchez Robayna viene peleando con una angustia secreta, ante los poderes del arte y la poesía; pero esta misma limitación es el fundamento de su voluntad creadora. Por eso, puede decir Sánchez Robayna: «La claridad es la serenidad» (Sánchez Robayna, 1996: 76) sin que se elimine por lo tanto factores residuales de la angustia. Lector atento de María Zambrano, Sánchez Robayna recoge algunas de sus enseñanzas, en particular, la necesidad

\footnotetext{
${ }^{5}$ Esta pregunta aparece reiteradas veces a lo largo de su diario La inminencia y el poeta aboga entonces por la escritura o sea la necesidad de escribir, manera no de fijar el tiempo, sino de situar el no-tiempo. Robayna comienza su diario por estos apuntes: «[...] Todo incipit como una duda, una indecisión esencial. Pero cualquier punto es igualmente válido. No hay centro, o el centro es ubicuo. ¿Cuál es el objeto de este cuaderno? Horror a toda fijación. La idea de un tiempo vacío, simultáneamente habitado e inalcanzable, inasible. Escribir en este tiempo - en este no-tiempo» (Sánchez Robayna, 1995: 15). El artista, gracias a la memoria o la imaginación, puede relacionarse con un tiempo que no tiene realidad propia.
} 
de escribir a partir de la conciencia -o sea lo invisible. Tal posicionamiento está bien explicado en Philosophie et poésie:

Dans l'angoisse du poète, par contre, il y a bien quelque chose qu'il se voit contraint de créer, parce qu'il s'est épris de sa présence sans la voir et que pour la voir et en jouir il doit la chercher. Le poète est amoureux de la présence de ce qu'il ne possède pas, et comme il ne le possède pas, il doit l'évoquer. (Zambrano, 2003: 129-130).

La «casa refugio», hacia la que camina el poeta, llega a ser la alegoría de la convergencia entre la materia y el espíritu que tan sólo puede sosegar el tormento; la casa simboliza entonces la intuición de un centro, un origen, un hontanar de energía, el lazo indefectible entre el yo y el mundo. Andrés Sánchez Robayna habrá logrado fijar una razón de esperar, tejiendo una constelación, nombrada en su obra como luz insular. Podría objetarse que esta esperanza no es más que un sueño ingenuo, pero constituye de por sí un hecho: es la raíz de la pulsión creadora.

\section{Bibliografía}

Champeau, S. (1995): Poésie et ontologie. Trois études sur les limites du langage. París, Vrin.

Collot, M. (2005): Paysage et poésie du romantisme à nos jours. París, José Corti.

LE Bigot, C. (2000): «Sobre la insularidad como referente y como metáfora en la poesía canaria», en Estudios canarios. Anuario del Instituto de Estudios canarios. Tenerife, ${ }^{\circ}$ XLIV, pp. 133-142.

LeVINAs, E. (1990): Totalité et infini. París, Le Livre de Poche, LGF, (1 $1^{\text {rè }}$ édition, 1971).

Merleau-Ponty, M. (2011): L'CEil et l'esprit. París, Gallimard, coll. Folio/essai, $1^{\text {ère }}$ ed. 1964.

Ruiz Casanova, J. F. (2012): Introducción a A. SÁnchez RobAyna, El espejo de tinta, (Antología 1970-2010). Madrid, Cátedra.

SÁnchez Robayna, A. (1996): La Inminencia. (Diarios, 1980-1995). Madrid, México, Fondo de Cultura Económica.

(2004): En el cuerpo del mundo. Obra poética (1970-2002). Barcelona, Galaxia Gutenberg/ Círculo de Lectores.

(2010): La sombra y la apariencia. Barcelona, Tusquets Editores.

Zambrano, M. (2003): Philosophie et poésie. París, Corti. Texte traduit par J. AnCET. 1 ére édition de Filosofía y poesía, 1939. 